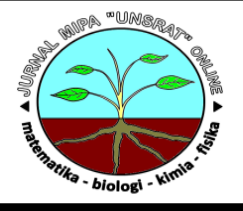

\title{
Penapisan Alkaloid Pada Tumbuhan Paku dari
} Halmahera Utara

\section{Muhammad Ikhlas Djorongaa*, Dingse Pandiangana, Febby Ester F.Kandoua, Agustina M.Tangapoa}

aJurusan Biologi, FMIPA, Unsrat, Manado

\begin{tabular}{ll}
\hline K A T A K U N C I & A B S T R A K \\
\cline { 2 - 3 } $\begin{array}{l}\text { Skrining alkaloid } \\
\text { Tumbuhan paku }\end{array}$ & Penelitian ini bertujuan untuk melakukan penapisan senyawa \\
Halmahera Utara & alkaloid pada beberapa jenis tumbuhan paku yang ditemukan di \\
& Halmahera Utara. Metoda yang digunakan untuk penelitian ini adalah \\
& metoda deskriptif, pengambilan sampel menggunakan teknik metoda \\
& jelajah di sepanjang jalan yang dilalui. Penapisan alkaloid menggunakan \\
& Reagen Mayer, Wagner dan Dragendorff, sampel yang digunakan dari \\
daun yang dewasa, sekitar 2 g. Hasil yang didapatkan sebanyak 70 \\
spesies sampel tumbuhan paku. Hasil penapisan alkaloid diperoleh 30 \\
spesies sampel yang positif mengandung alkaloid. Sampel tersebut \\
adalah Selaginella plana, Cyclopeltis sp., Diplazim dilatatum, Cyclosorus \\
sp., Tectaria angulata, Microlepia sp., Sphaerostephanus unitus, Pteris \\
tripartia, Blechinum sp.1, Nephrolepis biserrata, Selaginella sp.(daun \\
panjang), Diplazium esculentum, Sphaerosthanos sp., Asplenium serra, \\
Lomagramma sumatrana, Thelypteris dentata, Microsorum pteropus, \\
Tectaria sp.1, Nephrolepis undulata, Selaginella delicatula, Pityrogramma \\
calomelanos, Lycopodium phlegmaria, Loxogramme scolopendria, \\
Phyrrosia longifolia, Vittaria elongata, Psilotum sp., Elaphoglossum sp.1, \\
Elaphoglossum sp.2, Adiantum lunulatu dan ada satu spesies yang belum \\
teridentifikasi yaitu sp3.
\end{tabular}

K E Y W O R D S

Alkaloids screening

Ferns

North Halmahera
A B S T R A C T

This research to conduct screening of alkaloid compounds in some species of ferns found in North Halmahera. The method used for this research is descriptive method, sampling using the method cruising along the path traversed. Screening of alkaloids using reagents is Mayer, Wagner and Dragendorff, used samples of mature leaves, about 2 g. The results obtained were 70 species of fern samples. Only 30 species positive contain alkaloids. The sample is Selaginella plana, Cyclopeltis sp., Diplazim dilatatum, Cyclosorus sp., Tectaria angulata, Microlepia sp., Sphaerostephanus unitus, Pteris tripartia, Blechinum sp.1, Nephrolepis biserrata, Selaginella sp.(daun panjang), Diplazium esculentum, Sphaerosthanos sp., Asplenium serra, Lomagramma sumatrana, Thelypteris dentata, Microsorum pteropus, Tectaria sp.1, Nephrolepis undulata, Selaginella delicatula, Pityrogramma calomelanos, Lycopodium phlegmaria, Loxogramme scolopendria, Phyrrosia longifolia, Vittaria elongata, Psilotum sp., Elaphoglossum sp.1, Elaphoglossum sp.2, Adiantum lunulatu, and there is one species that has not been identified is Sp3. 


\section{Pendahuluan}

Indonesia merupakan salah satu negara yang memiliki kekayaan alam hayati yang sangat beranekaragam jenisnya, salah satunya yaitu tumbuhan paku. Diperkirakan tumbuhan paku mencapai \pm 10.000 jenis dan di Indonesia diperkirakan mencapai 3.000 jenis (Loveless, 1999 dalam Lubis, 2009). Sebagian masyarakat memanfaatkan tumbuhan paku sebagai tanaman hias, sayur, pupuk pada tanaman padi, untuk media tanaman anggrek, bahan patung dan sebagai obatobatan tradisional (Wardah dan Wiriadinata, 2000).

Banyak masyarakat belum mengetahui senyawa-senyawa aktif yang terdapat di dalam tumbuhan paku. Senyawa-senyawa aktif yang terdapat pada tumbuhan tersebut sangat banyak dan beragam salah satunya yaitu alkaloid. Hasil penelitian sebelumnya tentang tumbuhan paku yang dilaporkan mengandung alkaloid yaitu Selaginella willdonovii, Selaginella plana, Selaginella dan Nephrolepis radicans ornata (Chikamawati dan Miftahudin, 2008; Dayanti dan Suyatno, 2012; Piqqott \& Piqqott, 1988).

Alkaloid merupakan senyawa organik yang banyak ditemukan pada berbagai jenis tumbuhan, baik di bagian daun, biji, ranting dan kulit kayu (Pandiangan, 2009). Hampir semua alkaloid yang ditemukan di alam mempunyai keaktifan biologis tertentu, ada yang sangat beracun tetapi adapula yang sangat berguna dalam pengobatan, misalnya kuinin, morfin dan striknin (Pandiangan dan Kandou, 2006).

Bidang kesehatan alkaloid mempunyai efek berupa pemicu sistem saraf, menaikkan tekanan darah, mengurangi rasa sakit, antimikroba, obat penenang dan obat penyakit jantung (Robinson, 1995 dalam Simbala, 2008). Pada tumbuhan, alkaloid berfungsi sebagai pelindung dari serangga hama, penguat tumbuh-tumbuhan serta sebagai pengatur kerja hormon. Telah diketahui sekitar 5.500 senyawa alkaloid yang tersebar diberbagai suku (Harbone, 1987).

Penelitian yang telah dilakukan untuk mendapatkan senyawa kimia aktif dari tumbuhan paku telah banyak dilakukan. Namun penelitian yang membahas tentang penapisan alkaloid pada tumbuhan paku masih jarang dan khususnya di Halmahera Utara belum pernah dilakukan.

Berdasarkan latar belakang yang telah disampaikan di atas maka dapat diajukan permasalahannya dalam penelitian ini yaitu belum adanya pengkajian tentang jenis-jenis tumbuhan paku yang mengandung senyawa alkaloid dari Halmahera Utara, sehingga dilakukan penelitian tentang penapisan alkaloid pada tumbuhan paku tersebut. Penelitian ini bertujuan untuk melakukan penapisan senyawa alkaloid pada beberapa jenis tumbuhan paku yang ditemukan di Halmahera Utara.

\section{Metode}

\subsection{Tempat dan Waktu Penelitian}

Penelitian ini dilaksanakan bulan April-Juni 2014. Lokasi penelitian pengambilan sampel dilakukan di Halmahera Utara. Pengambilan sampel dilakukan di 3 kecamatan antara lain, Kecamatan Galela Selatan, Kecamatan Tobelo Utara dan Kecamatan Kao Utara. Pengujian senyawa alkaloid dilakukan di Laboratorium Fitokimia Farmasi MIPA UNSRAT.

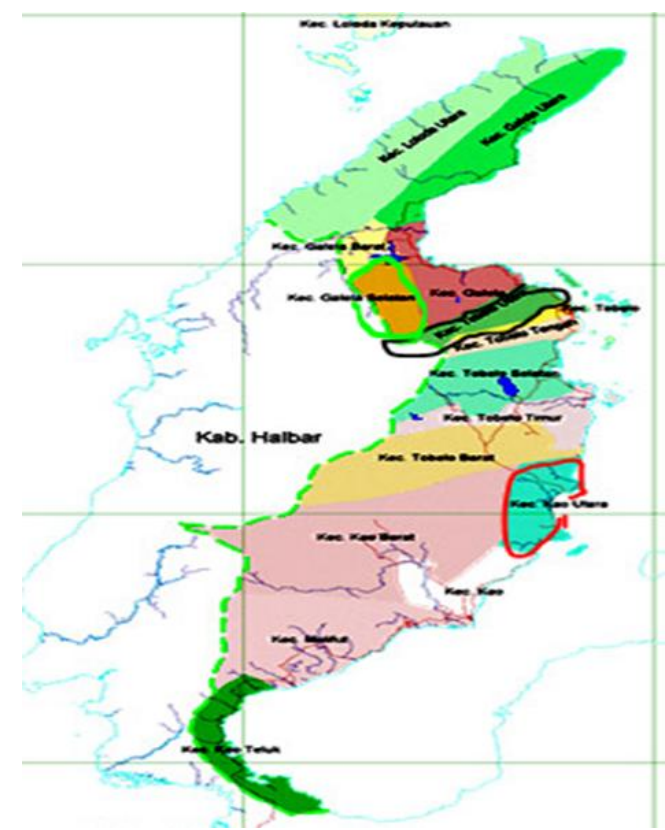

Gambar 1. Lokasi penelitian di Halmahera Utara.

\subsection{Material}

Peralatan yang digunakan gunting tanaman, kantong plastik, kertas label, buku catatan, buku identifikasi, pensil, kamera dan pisau cutter, tabung reaksi, batang pengaduk, corong, pipet tetes pasteur, gelas ukur, labu erlenmeyer, timbangan analitik, soil tester, pisau, mortal, tisu, kertas aluminium foil, pestel, sendok sampel dan kertas saring.

Bahan-bahan kimia untuk penapisan alkaloid yaitu sebagai berikut: Kloroform, $\mathrm{H} 2 \mathrm{SO} 4, \mathrm{HgCl} 2, \mathrm{KI}$, Asam asetat glasial, Bismuth sub nitrat, iodium, pereaksi Mayer, pereaksi Wagner, pereaksi Dragendorff, etanol dan aquades.

\subsection{Teknik Pengambilan Sampel}

Pengambilan sampel tumbuhan paku dilakukan pada tiga kecamatan yaitu di Kecamatan Galela Selatan, Kecamatan Tobelo Utara dan Kecamatan Kao Utara terutama di daerah yang lembab dan berhutan. Menggunakan metode Purposive Sampling, setiap kecamatan diambil sampel tumbuhan paku mewakili 3 desa. Sampel tumbuhan paku diambil secara utuh (akar, batang dan daun). Setelah itu ditaruh ke dalam kantong plastik lalu diberi label secara berurutan antara tempat dan spesies yang diperoleh. 
Sampel yang didapatkan dilapangan kemudian diidentifikasi dengan menggunakan buku tentang paku seperti buku Piqqott \& Piqqott (1988); de Winter \& Amoroso (2003); van Steenis (1988); Tjitrosoepomo (1989); dan Sastrapradja \& Afriastini (1985); Satrapradja et al., (1979); dan Parris et al., (2010), serta dari media internet. Identifikasi dilakukan dengan membandingkan antara ciri morfologi pada sampel dengan gambar yang terdapat di buku identifikasi dan media internet.

\subsection{Pembuatan Reagen}

Reagen Mayer dibuat dengan melarutkan sebanyak 1,36 g HgCl 2 dalam $60 \mathrm{~mL}$ aquades. Pada bagian lain dilarutkan $5 \mathrm{~g} \mathrm{KI}$ dalam $10 \mathrm{~mL}$ aquades, kemudian kedua larutan dicampurkan lalu diencerkan hingga volumenya menjadi $100 \mathrm{~mL}$ (Simbala, 2008). Reagen Wagner, dengan melarutkan sebanyak 1,27 g iodium dan $2 \mathrm{~g} \mathrm{Kl}$ dilarutkan dalam $5 \mathrm{~mL}$ aquades. Lalu larutan tersebut diencerkan menjadi $100 \mathrm{~mL}$ dengan aquades dan disimpan ke dalam botol yang berwarna gelap (Simbala, 2008). Reagen Dragendorff yaitu, sebanyak $8 \mathrm{~g} \mathrm{KI}$ dilarutkan ke dalam $20 \mathrm{~mL}$ aquades. Pada bagian lain 0,85 g bismut subnitrat dilarutkan dalam $10 \mathrm{~mL}$ asama (Harbone, 1987).
Pengujian senyawa alkaloid yang terdapat pada tumbuhan paku dilakukan dengan menggunakan metode Mayer, Wagner dan Dragendorff. Hasil uji alkaloid dengan metode Mayer yang positif mengandung alkaloid yaitu yang mengandung endapan berwarna putih didasar tabung, kemudian metode Wagner yang positif mengandung alkaloid yaitu yang mengandung endapan yang berwarna coklat hingga warna kuning, kemudian untuk metode Dragendorff yang positif mengandung alkaloid yaitu mengandung endapan berwarna merah bata (coklat hingga berwarna jingga).

Analisis data yang diperoleh disajikan dalam bentuk tabel dan gambar. Data ini berupa data analisis senyawa alkaloid pada beberapa jenis pakupakuan yang diambil dari beberapa tempat.

\section{Hasil dan Pembahasan \\ 3.1. Inventarisasi Tumbuhan Paku dari Halmahera Utara}

Hasil inventarisasi tumbuhan paku yang telah diperoleh dari Halmahera Utara sebanyak 70 spesies dapat dilihat pada Tabel 1.

Tabel 1. Jenis-jenis tumbuhan paku dari Halmahera Utara

\begin{tabular}{|c|c|c|c|c|c|}
\hline \multirow[b]{2}{*}{ No } & \multirow[b]{2}{*}{ Famili } & \multirow[b]{2}{*}{ Spesies } & \multicolumn{3}{|c|}{ Penapisan Alkaloid } \\
\hline & & & Mayer & Wagner & Dragendorff \\
\hline 1 & Selaginellaceae & Selaginella plana & $(+)(+)$ & $(+)(-)$ & $(+)(-)$ \\
\hline 2 & Dryopteridaceae & Elaphoglossum sp. & $(-)(-)$ & $(-)(-)$ & $(-)(-)$ \\
\hline 3 & Thelypteridacese & Cyclosorus heterocanpus & $(-)(-)$ & $(-)(-)$ & $(-)(-)$ \\
\hline 4 & Lomariopsidaceae & Cyclopeltis sp. & $(+)(+)$ & $(+)(+)$ & $(+)(+)$ \\
\hline 5 & Athyriaceae & Diplazim dilatatum & $(+)(+)$ & $(+)(+)$ & $(-)(-)$ \\
\hline 6 & Thelypteridaceae & Cyclosorus sp. & $(-)(+)$ & $(+)(+)$ & $(+)(+)$ \\
\hline 7 & Thelypteridaceae & Diplazium asperum & $(+)(-)$ & $(-)(-)$ & $(-)(-)$ \\
\hline 8 & Dryopteridaceae & Tectaria angulata & $(+)(+)$ & $(+)(+)$ & $(+)(+)$ \\
\hline 9 & Aspleniacese & Asplenium nidus & $(-)(-)$ & $(-)(-)$ & $(-)(-)$ \\
\hline 10 & Dennstaedtiaceae & Microlepiasp. & $(+)(+)$ & $(+)(+)$ & $(+)(+)$ \\
\hline 11 & Thelypteridacese & Sphaerostephanus unitus & $(+)(+)$ & $(+)(+)$ & $(+)(+)$ \\
\hline 12 & Pteridaceae & Pteris tripartia & $(+)(+)$ & $(+)(+)$ & $(+)(+)$ \\
\hline 13 & Davalliaceae & Davallia solida & $(-)(-)$ & $(-)(-)$ & $(-)(-)$ \\
\hline 14 & Blechnaceae & Blechinum sp. & $(+)(+)$ & $(+)(+)$ & $(+)(+)$ \\
\hline 15 & Dennstaedtiaceae & Hypolepis sp. & $(-)(-)$ & $(-)(-)$ & $(-)(-)$ \\
\hline 16 & Nephrolepidacese & Nephrolepis bisemata & $(+)(+)$ & $(+)(+)$ & $(+)(+)$ \\
\hline 17 & & $\mathrm{Sp} 1$ & $(-)(-)$ & $(-)(-)$ & $(-)(-)$ \\
\hline 18 & Woodsiaceae & Athyrium acendens & $(-)(-)$ & $(-)(-)$ & $(-)(-)$ \\
\hline 19 & Dryopteridaceae & Lomariopsis sp. & $(-)(-)$ & $(-)(-)$ & $(-)(-)$ \\
\hline 20 & Selaginellaceae & Selaginella sp. 2 & $(-)(-)$ & $(-)(-)$ & $(-)(-)$ \\
\hline 21 & Dryopteridaceae & Tectaria herpetocaulos & $(-)(-)$ & $(-)(-)$ & $(-)(-)$ \\
\hline 22 & Cyhateaceae & Chyateaexillis & $(-)(-)$ & $(-)(-)$ & $(-)(-)$ \\
\hline 23 & Nephrolepidaceae & Nephrolepis exaltata & $(-)(-)$ & $(-)(-)$ & $(-)(-)$ \\
\hline 24 & Thelypteridaceae & Christella sp. & $(-)(-)$ & $(-)(-)$ & $(-)(-)$ \\
\hline 25 & Dryopteridaceae & Tectaria sp. 2 & $(-)(-)$ & $(-)(-)$ & $(-)(-)$ \\
\hline 26 & & Sp 2 & $(-)(-)$ & $(-)(-)$ & $(-)(-)$ \\
\hline 27 & Selaginellaceae & Selaginella sp.1 & $(+)(+)$ & $(-)(-)$ & $(+)(+)$ \\
\hline 28 & Tectariaceae & Ctenitopsis subsagenia & $(-)(-)$ & $(-)(-)$ & $(-)(-)$ \\
\hline
\end{tabular}




\begin{tabular}{|c|c|c|c|c|c|}
\hline No & Famili & Spesies & Mayer & Wagner & Dragendorff \\
\hline 29 & Vittariaceae & Monogramma trichoidea & $(-)(-)$ & $(-)(-)$ & $(-)(-)$ \\
\hline 30 & Dryopteridaceae & Tectaria sp. 5 & $(-)(-)$ & $(-)(-)$ & $(-)(-)$ \\
\hline 31 & Pteridaceae & Pteris vittata & $(-)(-)$ & $(-)(-)$ & $(-)(-)$ \\
\hline 32 & Dryopteridaceae & Tectaria sp. 3 & $(-)(-)$ & $(-)(-)$ & $(-)(-)$ \\
\hline 33 & Thelypteridaceae & Diplazium esculentum & $(+)(+)$ & $(+)(+)$ & $(+)(+)$ \\
\hline 34 & Thelypteridaceae & Sphaerosthanos sp. & $(+)(+)$ & $(+)(+)$ & $(+)(+)$ \\
\hline 35 & Pteridaceae & Pteris longipinnula & $(-)(-)$ & $(-)(-)$ & $(-)(-)$ \\
\hline 36 & Aspleniaceae & Asplenium sema & $(+)(+)$ & $(+)(+)$ & $(+)(+)$ \\
\hline 37 & Dryopteridaceae & Elaphoglossum paleaceum & $(-)(-)$ & $(-)(-)$ & $(-)(-)$ \\
\hline 38 & Nephrolepidaceae & Nephrolepis sp. 1 & $(-)(-)$ & $(-)(-)$ & $(-)(-)$ \\
\hline 39 & Lomariopsidaceae & Lomagramma sumatrana & $(+)(+)$ & $(+)(+)$ & $(+)(+)$ \\
\hline 40 & Thelypteridaceae & Thelypteris dentata & $(+)(-)$ & $(+)(+)$ & $(+)(+)$ \\
\hline 41 & & Sp.3 & $(+)(+)$ & $(+)(+)$ & $(-)(+)$ \\
\hline 42 & Dryopteridacese & Pleocnemia irregularis & $(-)(-)$ & $(-)(-)$ & $(-)(-)$ \\
\hline 43 & Polypodiaceae & Microsorum pteropus & $(+)(+)$ & $(+)(+)$ & $(+)(+)$ \\
\hline 44 & Dryopteridaceae & Tectaria sp.1 & $(+)(+)$ & $(+)(+)$ & $(+)(+)$ \\
\hline 45 & Pteridaceae & Pteris biaurita & $(-)(-)$ & $(-)(-)$ & $(-)(-)$ \\
\hline 46 & Nephrolepidaceae & Nephrolepis undulata & $(+)(-)$ & $(+)(+)$ & $(+)(+)$ \\
\hline 47 & Selaginellaceae & Selaginella delicatula & $(+)(+)$ & $(+)(-)$ & $(+)(+)$ \\
\hline 48 & Polypodiaceae & Pityrogramma calomelanos & $(+)(+)$ & $(+)(+)$ & $(+)(+)$ \\
\hline 49 & Aspleniacese & Asplenium sp.1 & $(-)(-)$ & $(-)(-)$ & $(-)(-)$ \\
\hline 50 & Pteridaceae & Agrosticum aureum & $(-)(-)$ & $(-)(-)$ & $(-)(-)$ \\
\hline 51 & Polypodiaceae & Lycopodium phlegmaria & $(+)(-)$ & $(+)(+)$ & $(+)(+)$ \\
\hline 52 & Polypodiaceae & Loxogramme scolopenária & $(-)(-)$ & $(+)(+)$ & $(+)(+)$ \\
\hline 53 & Marattiaceae & Angiopteris evecta & $(-)(-)$ & $(-)(-)$ & $(-)(-)$ \\
\hline 54 & Aspleniacese & Asplenium sp.2 & $(-)(-)$ & $(-)(-)$ & $(-)(-)$ \\
\hline 55 & Dryopteridaceae & Tectaria sp.4 & $(-)(-)$ & $(-)(-)$ & $(-)(-)$ \\
\hline 56 & Polypodiaceae & Phymosia longifolia & $(+)(+)$ & $(+)(+)$ & $(+)(+)$ \\
\hline 57 & Polypodiaceae & Microlepia herbacea & $(-)(-)$ & $(-)(-)$ & $(+)(-)$ \\
\hline 58 & Hymenophyllaceae & Trichomanes maxium & $(-)(-)$ & $(-)(-)$ & $(-)(-)$ \\
\hline 59 & Hymenophyllaceae & Trichomanes javanicum & $(-)(-)$ & $(-)(-)$ & $(-)(-)$ \\
\hline 60 & Vittariacese & Vittaria elongata & $(+)(-)$ & $(+)(-)$ & $(+)(+)$ \\
\hline 61 & Psilotaceae & Psilotum sp. & $(+)(+)$ & $(-)(-)$ & $(+)(+)$ \\
\hline 62 & Pteridaceae & Antrophylum parvulu & $(-)(-)$ & $(-)(-)$ & $(-)(-)$ \\
\hline 63 & Dryopteridaceae & Elaphoglossum sp.1 & $(+)(+)$ & $(+)(+)$ & $(+)(+)$ \\
\hline 64 & Dryopteridaceae & Elaphoglossum sp.2 & $(+)(+)$ & $(+)(+)$ & $(+)(+)$ \\
\hline 65 & Lygodiaceae & Lygodium japonicum & $(-)(-)$ & $(-)(-)$ & $(-)(-)$ \\
\hline 66 & Pteridaceae & Adiantum lunulatum & $(+)(-)$ & $(+)(+)$ & $(+)(+)$ \\
\hline 67 & Polypodiaceae & Drinaria sp. & $(-)(-)$ & $(-)(-)$ & $(-)(-)$ \\
\hline 68 & Blechnaceae & Stenochlaena palustris & $(-)(-)$ & $(-)(-)$ & $(-)(-)$ \\
\hline 69 & Pteridaceae & Pteris multifida & $(-)(-)$ & $(-)(-)$ & $(-)(-)$ \\
\hline 70 & Lygodiaceae & Lvgodium palmatum & $(-)(-)$ & $(-)(-)$ & $(-)(-)$ \\
\hline \multicolumn{6}{|c|}{ Keterangan ; $(+)=$ Terdeteksi alkaloid (a da endapan) } \\
\hline & & & & & \\
\hline
\end{tabular}

Hasil yang didapatkan dari Desa Togawa Besi 25 spesies, Desa Togawa Baru 17 spesies dan Desa Seki didapatkan 12 spesies dengan total spesies yang didapatkan di Kecamatan Galela Selatan sebanyak 54 spesies. Hal tersebut dikarenakan kelembabannya 60\%-70\% dan daerahnya masih banyak terdapat hutan-hutan yang lembab serta sungai dan pegunungan. Karena sebagian besar tumbuhan paku sangat menyukai tempat-tempat yang teduh dengan derajat kelembaban yang tinggi (Tjitrosoepomo, 1994 dalam Arini dan Kinho, 2008).

Hasil yang didapatkan dari Desa Luari 4 spesies, Desa Ruko 2 spesies, sedangkan di Desa
Popilo spesies yang tumbuhan paku yang ditemukan sudah sama dengan spesies-spesies sebelumnya. Total spesies yang didapatkan hanya 6 spesies. Karena lokasi yang ke 2, memiliki daerah yang kebanyakan berbatu angus sekitar $50 \%$ dan jarangnya hutan-hutan yang lembab, serta luas tanah di daerah tersebut sebagian besar sudah dibuat perkebunan kelapa sehingga sudah jarang didapatkan hutan.

Hasil yang didapatkan di Desa Bobale 4 spesies, Desa Bori 5 spesies dan di Desa Boulamo hanya 1 spesies. Total spesies tumbuhan paku yang didapatkan dari Kecamatan Kao yaitu 10 spesies. 
Geografis pada lokasi ke 3 ini hampir mirip dengan lokasi yang ke 2, banyak terdapat bebatuan, sehingga hanya sedikit spesies tumbuhan paku yang didapatkan.

\subsection{Hasil Uji Penapisan Alkaloid (kualitatif)}

Pengujian alkaloid dengan mengikuti metoda dari Pandiangan dan Kandou (2006). Penelitian dilakukan dengan dua kali ulangan.

Hasil yang didapatkan dari uji penapisan yaitu sebanyak 30 spesies tumbuhan paku yang positif mengandung alkaloid, hasil tersebut dapat dilihat pada Tabel 2. Proses pertumbuhan terdapat dua sistem metabolisme yaitu metabolisme primer dan sekunder. Metabolisme sekunder menghasilkan produk metabolit sekunder yaitu alkaloid, flavanoid, tannin, saponin dan terpenoid. Proses metabolisme primer melibatkan senyawa-senyawa yang disebut metabolit primer di antaranya polisakarida, protein, lemak dan asam nukleat (Pandiangan, 2009).

Tabel 2. Spesies-spesies tumbuhan paku yang mengandung alkaloid

\begin{tabular}{|c|c|c|c|c|}
\hline \multirow[b]{2}{*}{ No } & \multirow[b]{2}{*}{ Spesies } & \multicolumn{3}{|c|}{ Penapisan Alkaloid } \\
\hline & & Mayer & Wagner & Dragendorff \\
\hline 1 & Adiantum lunulatu & $(+)(-)$ & $(+)(+)$ & $(+)(+)$ \\
\hline 2 & Asplenium sema & $(+)(+)$ & $(+)(+)$ & $(+)(+)$ \\
\hline 3 & Blechinum sp. & $(+)(+)$ & $(+)(+)$ & $(+)(+)$ \\
\hline 4 & Cyclopeltis sp. & $(+)(+)$ & $(+)(+)$ & $(+)(-)$ \\
\hline 5 & Cyclosorus sp. & $(-)(+)$ & $(+)(+)$ & $(+)(+)$ \\
\hline 6 & Diplazium esculentum & $(+)(+)$ & $(+)(+)$ & $(+)(+)$ \\
\hline 7 & Diplazim dilatatum & $(+)(+)$ & $(+)(+)$ & $(-)(-)$ \\
\hline 8 & Elaphoglossum sp.1 & $(+)(+)$ & $(+)(+)$ & $(+)(+)$ \\
\hline 9 & Elaphoglossum sp.2 & $(+)(+)$ & $(+)(+)$ & $(+)(+)$ \\
\hline 10 & Lycopodium phlegmaria & $(+)(-)$ & $(+)(+)$ & $(+)(+)$ \\
\hline 11 & Loxogramme scolopendria & $(-)(-)$ & $(+)(+)$ & $(+)(+)$ \\
\hline 12 & Lomagramma sumatrana & $(+)(+)$ & $(+)(+)$ & $(+)(+)$ \\
\hline 13 & Nephrolepis undulata & $(+)(-)$ & $(+)(+)$ & $(+)(+)$ \\
\hline 14 & Nephrolepis bisemata & $(+)(+)$ & $(+)(+)$ & $(+)(+)$ \\
\hline 15 & Microsorum pteropus & $(+)(+)$ & $(+)(+)$ & $(+)(+)$ \\
\hline 16 & Microlepiasp. & $(+)(+)$ & $(+)(+)$ & $(+)(+)$ \\
\hline 17 & Phymosia longifolia & $(+)(+)$ & $(+)(+)$ & $(+)(+)$ \\
\hline 18 & Pteris tripartia & $(+)(+)$ & $(+)(+)$ & $(+)(+)$ \\
\hline 19 & Psilotum sp. & $(+)(+)$ & $(-)(-)$ & $(+)(+)$ \\
\hline 20 & Piturogramma calomelanos & $(+)(+)$ & $(+)(+)$ & $(+)(+)$ \\
\hline 21 & Selaginella plana & $(+)(+)$ & $(+)(-)$ & $(-)(+)$ \\
\hline 22 & Selaginella delicatula & $(+)(+)$ & $(+)(-)$ & $(+)(+)$ \\
\hline 23 & Selaginella sp.(daun panjang) & $(+)(+)$ & $(-)(-)$ & $(+)(+)$ \\
\hline 24 & Sphaerostephanus unitus & $(+)(+)$ & $(+)(+)$ & $(+)(+)$ \\
\hline 25 & Sphaerosthanos sp. & $(+)(+)$ & $(+)(+)$ & $(+)(+)$ \\
\hline 26 & Tectaria angulata & $(+)(+)$ & $(+)(+)$ & $(+)(+)$ \\
\hline 27 & Tectaria sp.1 & $(+)(+)$ & $(+)(+)$ & $(+)(+)$ \\
\hline 28 & Thelypteris dentata & $(+)(-)$ & $(+)(+)$ & $(+)(+)$ \\
\hline 29 & Vittaria elongata & $(+)(+)$ & $(+)(-)$ & $(+)(+)$ \\
\hline 30 & Sp.3 & $(+)(+)$ & $(+)(+)$ & $(-)(+)$ \\
\hline
\end{tabular}

Keterangan; $(+)(+)=$ Terdeteks $i$, banyak endapan

$$
\begin{aligned}
& (+)(-)=\text { Lemah terdeteksi, endapan sedikit } \\
& (-)(-)=\text { Tidak terdeteksi }
\end{aligned}
$$

Senyawa aktif pada tumbuhan paku sangatlah banyak dan beragam, salah satunya senyawa alkaloid. Secara sederhana alkaloid dirujuk sebagai metabolit sekunder yang keberadaannya hanya pada spesies-spesies tertentu (Simbala, 2008). Pada umumnya pertumbuhan tanaman pada tahun pertama alkaloid terdistribusi pada berbagai organ tanaman, akan tetapi dengan bertambah umur dari tanaman maka alkaloid hanya akan terlokalisir pada beberapa organ saja (Rahmat, 2013).

Senyawa metabolit sekunder pada tumbuhan berfungsi untuk mempertahankan diri dari kondisi lingkungan yang kurang menguntungkan, misalnya untuk mengatasi hama dan penyakit, sehingga beberapa tumbuhan membutuhkan senyawa metabolit tersebut, salah satunya yaitu alkaloid. Peranan atau fungsi alkaloid pada tumbuhan itu sendiri sebagai 
pelindung dari serangga hama, penguat tumbuh tumbuhan dan pengatur kerja hormon.

Hasil pengujian yang positif dengan menggunakan reagen Mayer, Wagner dan Dragendorff yang terbentuk endapan, hal tersebut diperkirakan karena kompleks kalium-alkaloid (Marliana et al., 2005). Spesies tumbuhan paku yang negatif diduga karena tidak mengandung senyawa alkaloid (Sangi et al., 2012). Sehingga hasil yang didapatkan ada yang positif dan ada yang negatif.

Hasil penapisan alkaloid pada beberapa sampel tumbuhan paku terdapat juga reaksi positif palsu, reaksi positif palsu sering terjadi pada pereaksi Dragendorff. Hal tersebut terjadi karena pada saat pengujian ekstrak, tidak hilangnya pelarut asam basa ketika dilakukan penyaringan. Reaksi positif palsu juga sering terjadi karena adanya protein yang mengendap pada saat dilakukan penambahan pereaksi yang mengandung logam berat. Dalam penapisan alkaloid digunakan pereaksi Mayer, Wagner dan Dragendorff karena pereaksi yang sering didasarkan pada kesanggupan dari alkaloid tersebut untuk bergabung dengan logamlogam yang mempunyai atom tinggi. Senyawa alkaloid umumnya ditemukan dalam kadar yang sangat kecil dan harus dipisahkan dari campuran senyawa yang rumit, yang berasal dari jaringan tubuh (Lenny, 2006).

\section{Kesimpulan}

Berdasarkan hasil yang telah didapatkan maka dapat disimpulkan bahwa jenis-jenis tumbuhan paku yang ditemukan dari Halmahera Utara sebanyak 70 spesies, dan hasil positif alkaloid yang terkandung didalamnya yaitu sebanyak 30 spesies. Diantaranya yaitu Selaginella plana, Cyclopeltis sp., Diplazim dilatatum, Cyclosorus sp., Tectaria angulata, Microlepia sp., Sphaerostephanus unitus, Pteris tripartia, Blechinum sp.1, Nephrolepis biserrata, Selaginella sp.(daun panjang), Diplazium esculentum, Sphaerosthanos sp., Asplenium serra, Lomagramma sumatrana, Thelypteris dentata, Microsorum pteropus, Tectaria sp.1, Nephrolepis undulata, Selaginella delicatula, Pityrogramma calomelanos, Lycopodium phlegmaria, Loxogramme scolopendria, Phyrrosia longifolia, Vittaria elongata, Psilotum sp., Elaphoglossum sp.1, Elaphoglossum sp.2, Adiantum lunulatu dan ada satu spesies yang belum teridentifikasi yaitu sp3..

\section{Daftar Pustaka}

Arini, D.I.D. dan Kinho, J. 2008. Keragaman Jenis Tumbuhan Paku (Pteridophyta) di Cagar Alam Gunung Ambang Sulawesi Utara. Manado. 2 (1): 17-40.

Chikamawati, T dan Miftahudin. 2008. Biodiversitas dan Potensi Marga Selaginella Sebagai Antioksidan dan Anti Kanker (Laporan Hasil Penelitian). LPPM.IPB.

Dayanti, R. dan Suyatno. 2012. Aktivitas Antioksidan Ekstrak Metanol Bagian Batang Tumbuhan Paku
Nephrolepis radicans. UNESA Jurnal of Chemistry : 1(01): 86-92.

Lubis, S.R. 2009. Keanekaragaman Dan Pola Distribusi Tumbuhan Paku di Hutan Wisata Alam Taman Edeng Kabupaten Toba Samosir Provinsi Sumatera Utara [Tesis]. Universitas Sumatera Utara, Medan.1-142.

de Winter, W.P. dan Amoroso, V.B. 2003. Plant Resources of South-East Asia no.15(2) Cryptogams : Ferns and Fern Allies. PROSEA Foundation Bogor. Indonesia.

Harbone, J.B. 1987. Metode Fitokimia. Terjemahan Padmawinata, K. Soediro, I. ITB. Bandung.

Lenny, S. 2006. Senyawa Flavonoida, Fenilpropanoida dan Alkaloid. USU Respiratori. Medan :1-20.

Marliana, S.D., Suryanti, V. dan Suyono. 2005. Skrining Fitokimia dan Analisis Kromatografi Lapis Tipis Komponen Kimia Buah Labu Siam (Sechium edule Jacq. Swartz.) dalam Ekstrak Etanol. Biofarmasi. UNS Surakarta. 3(1): 26-31.

Pandiangan, D. dan Kandou, F.E. 2006. Inventarisasi dan Penapisan Alkaloid Tumbuhan Obat Tradisional Suku Sanger di Sangihe Sulawesi Utara. Makalah Seminar Nasional Tumbuhan Obat yang dilaksanakan oleh farmasi UNPAD Bandung tanggal 24-27 September 2006 di Gedung. Graha Sanusi Padjajaran. Bandung.

Pandiangan, D. 2009. Produksi Metabolit Sekunder Alkaloid Secara In Vitro. UNPAD Press. Bandung. 12-15.

Parris, B.S., Kiew, R., Chung, R.C.K., Saw, L.G., dan Soepadmo, E. 2010. Flora of Peninsular Malaysia. Series I: Ferns and Lycophytes. Malaysia. 1-249.

Piggott, A.G. dan Piggott, C.J. 1988. Fern of Malaysia in Colour. Kuala Lumpur. Tropical Press SDN. BHD. Malaysia.

Rahmat, F. 2013. Inventarisasi, Identifikasi dan Skrining Alkaloid dari Tumbuhan Obat Yang Tumbuh di Taman Nasional Meru Betir [Skripsi]. FMIPA Universitas Airlangga. Surabaya. 5-24.

Sangi, M.S., Momuat, L.I., dan Kumaunang, M. 2012. Uji Toksisitas dan Skrining Fitokimia Tepung Gabah Pelepah Aren (Arenga pinnata). Jurnal IImiah Sains. UNSRAT 12(02): 128-134.

Sastrapradja, S., dan Afriastini, J.J. 1985. Kerabat Paku. LIPI. Bogor. 3-103.

Sastrapradja, S., Afriastini, J.J., Darnaedi, D., dan Widjaja, E.A. 1979. Jenis Paku Indonesia. LIPI. Bogor.

Simbala, H.E.I. 2008. Analisis Senyawa Alkaloid Beberapa Jenis Tumbuhan Obat sebagai Bahan Aktif Fitofarmaka. Jurnal Pacific. 1(1): 489-494.

Tjitrosoepomo, G. 1989. Taksonomi Tumbuhan (Schozophyta, Thallophyta, Bryophyta, Pteridophyta). Gadjah Mada University Press. Yogyakarta. 219-305.

van Steenis, C.G.G.J. 1988. Flora. Pradnya Paramita. Jakarta. 80-100.

Wardah dan Wiriadinata, H. 2000. Lycopodium, Potensinya sebagai tanaman hias. balitbang botani, Puslitbang Biologi - LIPI. Bogor. 329-333. 